Marianne Debrunner

Ernst Schuiki

Elisabeth Minder

Edwin Straumann

Barbara Naegeli

Raymond Mury

Osmund Bertel

Jürgen Frielingsdorf

\section{Proinflammatory cytokines in acute myocardial infarction with and without cardiogenic shock}

Received: 9 April 2007

Accepted: 20 November 2007

Published online: 28 December 2007
M. Debrunner, MD - E. Schuiki, MD

E. Straumann, MD - B. Naegeli, MD

R. Mury, MD - O. Bertel, MD

J. Frielingsdorf, MD ( $\square)$

Division of Cardiology

Department of Internal Medicine

Stadtspital Triemli

Birmensdorferstrasse 497

8063 Zurich, Switzerland

Tel.: +41-44/466-1313

Fax: +41-44/466-2599

E-Mail: juergen.frielingsdorf@triemli.stzh.ch

E. Minder, MD

Central Laboratory

Stadtspital Triemli

8063 Zurich, Switzerland
Abstract Background Inflammatory response is an important feature of acute coronary syndromes and myocardial infarction (MI). The prognostic value of proinflammatory cytokines in patients with acute MI complicated by cardiogenic shock is unknown. Methods and results In 41 patients admitted with acute MI (age $60 \pm 11$ years, six females, 19 Killip class IV) serial plasma concentration of tumor necrosis factor alpha (TNF- $\alpha$ ), interleukin 6 (IL-6) and interleukin 1 receptor antagonist (IL$1 \mathrm{Ra})$ were measured. Seven patients with cardiogenic shock (CS) developed a systemic inflammatory response syndrome (SIRS). Patients with CS-particularly those who developed SIRS - showed significantly higher cytokine levels than patients with uncomplicated MI. In patients with CS and SIRS peak levels of IL-1Ra were $223,973 \mathrm{pg} / \mathrm{ml}$, IL-6 $252.8 \mathrm{pg} / \mathrm{ml}$ and TNF- $\alpha 7.0 \mathrm{pg} / \mathrm{ml}$. In CS without SIRS IL-1Ra levels were $19,988 \mathrm{pg} / \mathrm{ml}, \mathrm{IL}-6109.3 \mathrm{pg} / \mathrm{ml}$ and TNF- $\alpha 3.8 \mathrm{pg} / \mathrm{ml}$. In uncomplicated MI peak IL-1Ra levels were $1,088 \mathrm{pg} / \mathrm{ml}$, IL-6 $34.1 \mathrm{pg} / \mathrm{ml}$ and TNF- $\alpha$ $2.6 \mathrm{pg} / \mathrm{ml}$. Conclusions The inflammation-associated cytokines TNF- $\alpha$, IL-6 and IL-1Ra are significantly elevated in patients with MI complicated by CS when compared to patients with uncomplicated MI. Among shockpatients IL-1Ra levels are promising diagnostic markers for early identification of patients developing SIRS, heralding a poor outcome.

Key words interleukins - inflammation - infarction - prognosis shock

\section{Introduction}

Cardiogenic shock (CS) is the leading cause of death in patients hospitalized with acute myocardial infarction (AMI). Early revascularization strategies and the use of intra-aortic balloon counterpulsation have improved outcome but the prognosis remains poor $[17,18]$. The SHOCK trial showed a significant benefit for patients who underwent early revascularization after one-year follow-up. The survival rate however remains low with $46.7 \%$ at 1 year even with aggressive treatment [18]. Patients at greatest risk of \% death can be identified to some degree by using clinical and hemodynamic data [13]. These determinants of death are complex and interconnected. Besides hemodynamic and clinical factors also immunological processes likely influence course and outcome in patients with CS. In acute MI signs of inflammation are well known and elevated levels of acute phase reactants have been shown to be associated with a worse short- and long-term prognosis [24]. Signs of a systemic inflammatory response such as fever, leucocytosis and elevated acute phase reactants are frequently observed in patients with $\mathrm{MI}$ and CS. In patients with extensive myocardial infarctions a pronounced inflammatory response may further 
complicate the clinical course [19]. The associated clinical findings may be fully compatible with a systemic inflammatory response syndrome. The hemodynamic response to a systemic inflammatory response syndrome (SIRS) is particularly detrimental in this setting the setting of AMI. The release of proinflammatory cytokines like interleukin 1 (IL-1), interleukin 6 (IL-6) and tumor necrosis factor alpha $(\mathrm{TNF}-\alpha)$ is known to play a pivotal role in the development of SIRS [32]. We examined the inflammatory response of patients with uncomplicated MI and acute MI with cardiogenic shock by measuring plasma levels of IL- 6 , TNF- $\alpha$ and interleukin 1 receptor antagonist (IL-1Ra). A main aspect of our study was to determine whether the elevation of proinflammatory cytokines allows to identify patients who are developing SIRS early on in the course of disease.

\section{Methods}

\section{Patient population}

This prospective study consisted of a cohort undergoing acute percutaneous coronary intervention for AMI which was enrolled in the years 2001-2003. The study group comprised 41 consecutive patients presenting with AMI within $24 \mathrm{~h}$ after the onset of chest pain. The diagnosis of AMI was based on a history of acute chest pain lasting for more than $30 \mathrm{~min}$ and persistent ST segment elevation on the ECG. Transmural infarction was confirmed by serial electrocardiographic abnormalities, with the development of $Q$ waves lasting $0.04 \mathrm{~s}$ or longer as well as typical rise and fall in levels of cardiac markers (e.g., CK, CKMB, troponin I and myoglobin). In all patients acute coronary angiography revealed an occluded coronary artery that was suitable for recanalization by PTCA and all patients were successfully treated with angioplasty. All 41 patients underwent acute percutaneous coronary intervention (PCI) with successful recanalization and stenting of the infarct related vessel. The ejection fraction was measured in 29 patients invasively by levocardiography after PCI and in 12 patients by transthoracic echocardiography, measured within $12 \mathrm{~h}$ after admission. All patients survived the first $48 \mathrm{~h}$.

The patients were divided into three groups according to clinical and hemodynamic findings: group 1 included 22 patients with uncomplicated AMI, group 2 comprised 12 patients with AMI complicated by CS (within $36 \mathrm{~h}$ after admission) and group 3 seven patients who developed SIRS within $24 \mathrm{~h}$ after AMI with CS. Shock patients were taken consecutively. Patients in group 1 were chosen prospectively for comparison and matched for sex, age, and infarct localization from the prospective registry which included all patients with acute myocardial infarction.

Nineteen of the patients enclosed were in shock by clinical and hemodynamic criteria. The clinical criteria were hypotension (systolic blood pressure of $<90 \mathrm{mmHg}$ for at least $30 \mathrm{~min}$ or the need for supportive measures to maintain a systolic blood pressure of $>90 \mathrm{mmHg}$ ) and end-organ hypoperfusion (cool extremities or a urine output of $<30 \mathrm{ml}$ per h, and a heart rate of $>60$ beats per min). The hemodynamic criteria were a cardiac index of no more than 2.21 per min per square meter of body surface area and a pulmonary-capillary wedge pressure of at least $15 \mathrm{mmHg}$. A systemic inflammatory response was definded by $>2$ of the following conditions: temperature $>38^{\circ} \mathrm{C}$ or $<36^{\circ} \mathrm{C}$, heart rate $>90$ beats/min, respiratory rate $>20$ breath $/ \mathrm{min}$ or $\mathrm{PaCO} 2<32$ torr $(<4.3 \mathrm{kPa})$, white blood cell count $>12,000$ cells $/ \mathrm{mm}^{3}$, $<4,000$ cells $/ \mathrm{mm}^{3}$ or $>10 \%$ immature (band) cells. A heart rate above 90 (and not above 100) beats/min was chosen for the definition of SIRS in the present study because heart rate is usually influenced by age, sedation, and pre-interventional therapy with betablockers. In every patient standard intensive care was performed which included the implantation of an intra-aortic balloon pump if it was feasible (not limited by vessel access problems). Especially no specific measures were taken to modulate an inflammatory response (non-steroidal anti-inflammatory drugs, steroids).

The exclusion criteria were a history of a chronic inflammatory disease, evidence of bacterial infection based on clinical or laboratory findings (fever $>38.5^{\circ} \mathrm{C}$; CRP > 50; obvious local infection, e.g., abscess, positive blood cultures during the hospital course), history of cardiac surgery, severe trauma, burns or acute pancreatitis within the past four weeks, immunosuppression or malignancies. The study was approved by the local Ethics Committee and written informed consent was obtained from patients or from their closest relatives.

\section{Blood collection}

The first blood sample was taken before PTCAPCI. During the revascularization procedure further blood samples were obtained hourly in the catheter laboratory and after the patient was transferred to the intensive care unit (ICU) two-hourly until peak CK-MB was reached. The inflammatory response was assessed by measuring TNF- $\alpha$, IL-6, IL-1Ra and C-reactive protein (CRP). Cardiac markers including $\mathrm{CK}, \mathrm{CK}-\mathrm{MB}$, troponin I and myoglobin were checked simultaneously with these immunological 
markers to give an estimate of the myocardial cell damage.

\section{Laboratory assays}

Plasma samples for cytokines were stored at $-20^{\circ} \mathrm{C}$ prior to analysis. IL-1Ra, IL- 6 and TNF- $\alpha$ were measured by commercially available assays (Quantikine, R\&D Systems, Minneapolis, Minnesota). Cardiac enzymes and CRP were measured immediately by standard laboratory techniques.

The upper normal level for IL-1Ra was $598 \mathrm{pg} / \mathrm{ml}$ (mean $291 \pm 154 \mathrm{pg} / \mathrm{ml}$ ), for IL-6 $4.5 \mathrm{pg} / \mathrm{ml}$ (mean $1.9 \pm 0.6 \mathrm{pg} / \mathrm{ml}$ ) and for TNF- $\alpha 1.86 \mathrm{pg} / \mathrm{ml}$ (mean $0.95 \pm 0.46 \mathrm{pg} / \mathrm{ml}$ ).

\section{Statistical analysis}

Because data were not distributed normally, nonparametric tests were used. Results are expressed as mean \pm standard deviation or median as appropriate. For continuous variables the Mann-Whithney $U$ test was used to evaluate differences among groups. For categorical variables, a $\chi^{2}$ test was used. A probability value of $p<0.05$ was assumed to be significant.

Table 1 Patient's demographic and angiographic characteristics

\begin{tabular}{|c|c|c|c|c|}
\hline & $\begin{array}{l}\text { All patients } \\
(n=41)\end{array}$ & $\begin{array}{l}\text { Group } 1 \\
(n=22)\end{array}$ & $\begin{array}{l}\text { Group 2 } \\
(n=12)\end{array}$ & $\begin{array}{l}\text { Group } 3 \\
(n=7)\end{array}$ \\
\hline Mean age y & $60 \pm 11$ & $57 \pm 12$ & $64 \pm 9$ & $59 \pm 9$ \\
\hline Gender M/F & $35 / 6$ & $20 / 2$ & & $6 / 1$ \\
\hline Body mass index $\mathrm{kg} / \mathrm{m}^{2}$ & $27 \pm 4$ & $27 \pm 4$ & $25 \pm 3$ & $28 \pm 3$ \\
\hline \multicolumn{5}{|c|}{ Cardiovascular risk factors $n$} \\
\hline Family history & 13 & 9 & 3 & 1 \\
\hline Hypercholesterolemia & 27 & 15 & 8 & 4 \\
\hline Diabetes mellitus & 11 & $5^{\mathrm{a}}$ & 2 & 4 \\
\hline Hypertension & 16 & 6 & 6 & 4 \\
\hline Smoking & 30 & 15 & 10 & 5 \\
\hline \multicolumn{5}{|c|}{ Location of myocardial infarction $n$} \\
\hline Anterior & 24 & 16 & $5^{\mathrm{b}}$ & 3 \\
\hline Inferior & 17 & 5 & 7 & 5 \\
\hline Right-heart involvement & 5 & 1 & 3 & 1 \\
\hline Ejection fraction \% & $46 \pm 18$ & $53 \pm 16^{c}$ & $44 \pm 17^{c}$ & $24 \pm 7$ \\
\hline \multicolumn{5}{|l|}{ Angiography $n$} \\
\hline Single-vessel disease & 15 & 11 & 3 & 1 \\
\hline Multi-vessel disease & 26 & 11 & 9 & 6 \\
\hline Time to recanalization min & $460 \pm 392$ & $407 \pm 367$ & $391 \pm 252$ & $767 \pm 588$ \\
\hline \multicolumn{5}{|c|}{ Final TIMl flow } \\
\hline 0 & 0 & 0 & 0 & 0 \\
\hline 1 & 1 & 0 & 1 & 0 \\
\hline 2 & 2 & 1 & 2 & 0 \\
\hline 3 & 37 & 21 & 9 & 7 \\
\hline No reflow & 1 & 0 & 1 & 0 \\
\hline
\end{tabular}

${ }^{a}$ Group 1 vs. group 2, $p=0.026$

${ }^{\mathrm{b}}$ Group 2 vs. group 3, $p=0.012$

${ }^{c}$ Group 1 vs. group 3, $p=0.0008$; group 2 vs. group 3, $p=0.03$

\section{Results}

\section{Patient characteristics}

The three groups did not differ with respect to age, BMI and success rate of revascularization (Table 1). In the three groups delay between onset of symptoms and time of revascularization did not differ significantly. Patients with CS and SIRS showed a trend towards a longer delay between onset of symptoms and time of recanalization. This difference, however, was not statistically significant (Table 1). Final TIMI flow was comparable in all three groups (Table 1).

With the exception of myoglobin and CK in group 3 , cardiac markers were only modestly elevated at baseline (Table 2). The median peak plasma CK concentration of all patients was 2,845 IU/l, with higher levels found in group $2(3,236 \mathrm{IU} / \mathrm{l})$ and group $3(7,248 \mathrm{IU} / \mathrm{l})$ expressing the larger extent of myocardial damage in these groups (Table 3). The three groups did not differ with respect to age, BMI and success rate of revascularization. The left ventricular ejection fraction was significantly lower in group 3 (CS and SIRS, $24 \pm 7 \%$ ) than in group 1 (LVEF $53 \pm 16 \%$ ) and group 2 (LVEF $44 \pm 17 \%$ ), respectively (uncomplicated AMI). Systolic function did not differ between patients with cardiogenic shock with-

Table 2 Cardiac markers and cytokine levels at baseline

\begin{tabular}{llllllll}
\hline Markers & Group 1 & Group 2 & Group 3 & $p$-values & \\
\cline { 6 - 7 } & & $n=22$ & $n=12$ & $n=7$ & 1 vs. 2 & 1 vs. 3 & 2 vs. 3 \\
\hline CK IU/I & 488 & 224 & 1,508 & 0.7 & 0.11 & 0.13 \\
CKMB IU/I & 61 & 46 & 303 & 0.7 & 0.04 & 0.05 \\
Troponin $\mu \mathrm{g} / \mathrm{I}$ & 1.3 & 1.0 & 3.8 & 0.8 & 0.15 & 0.12 \\
Myoglobin nmol/I & 7.8 & 14.1 & 126 & 0.3 & 0.0008 & 0.09 \\
IL-1Ra pg/ml & 590 & 887 & 73,628 & 0.03 & $<0.0001$ & 0.001 \\
IL-6, pg/ml & 12.8 & 33.4 & 93.5 & 0.08 & 0.0003 & 0.09 \\
TNF- $\alpha \mathrm{pg} / \mathrm{ml}$ & 1.8 & 1.7 & 3.5 & 0.4 & 0.0024 & 0.08 \\
CRP mg/l & 4.0 & 10.0 & 15.0 & 0.02 & 0.06 & 0.7 \\
\hline
\end{tabular}

Data are presented as medians of baseline values

Table 3 Peak cardiac markers and cytokine levels

\begin{tabular}{|c|c|c|c|c|c|c|}
\hline \multirow[t]{2}{*}{ Markers } & \multirow{2}{*}{$\begin{array}{l}\text { Group } 1 \\
n=22\end{array}$} & \multirow{2}{*}{$\begin{array}{l}\text { Group } 2 \\
n=12\end{array}$} & \multirow{2}{*}{$\begin{array}{l}\text { Group } 3 \\
n=7\end{array}$} & \multicolumn{3}{|c|}{$p$-values } \\
\hline & & & & 1 vs. 2 & 1 vs. 3 & 2 vs. 3 \\
\hline CK IU, & 2,448 & 3,236 & 7,248 & 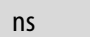 & .032 & ns \\
\hline CKMB IU/I & 292 & 289 & 1,059 & ns & 0.017 & 0.023 \\
\hline Troponin $\mu \mathrm{g} / \mathrm{l}$ & 37.2 & 18 & 58 & ns & ns & 0.063 \\
\hline Myoglobin $\mathrm{nmol} / \mathrm{l}$ & 31.9 & 128.5 & 368 & 0.066 & 0.003 & ns \\
\hline IL-1Ra pg/ml & 1,088 & 19,988 & 223,973 & 0.0006 & $<0.0001$ & 0.0005 \\
\hline IL-6 pg/ml & 34.1 & 109.3 & 252.8 & 0.0026 & 0.0008 & ns \\
\hline TNF- $\alpha \mathrm{pg} / \mathrm{ml}$ & 2.6 & 3.8 & 7.0 & 0.037 & 0.012 & ns \\
\hline CRP $\mathrm{mg} / \mathrm{l}$ & 35 & 102 & 189 & 0.057 & 0.007 & 0.052 \\
\hline
\end{tabular}

Data are presented as medians of peak values 
out SIRS, and patients with uncomplicated MI (Table 1). None of the patients in group 1 and only one patient in group 2 died during hospitalization. In group 3 the in-hospital-mortality was $71 \%$.

\section{Cytokine concentrations}

The baseline, serial, and peak plasma concentrations of proinflammatory cytokines IL-1Ra, IL- 6 and TNF- $\alpha$ are shown in Fig. 1 and Tables 2 and 3, respectively.

\section{IL-1Ra}

Among all inflammatory markers measured, the plasma concentrations of IL-1Ra showed the most impressive changes. A rise and fall of plasma levels can be observed particularly in patients with cardiogenic shock. Peak plasma concentrations in these patients are found 1-4 h after admission (Fig. 1).

In group 1 , the median peak value of IL-1Ra was with $1,088 \mathrm{pg} / \mathrm{ml}$ (range $438-26,379 \mathrm{pg} / \mathrm{ml}$ ) substan-
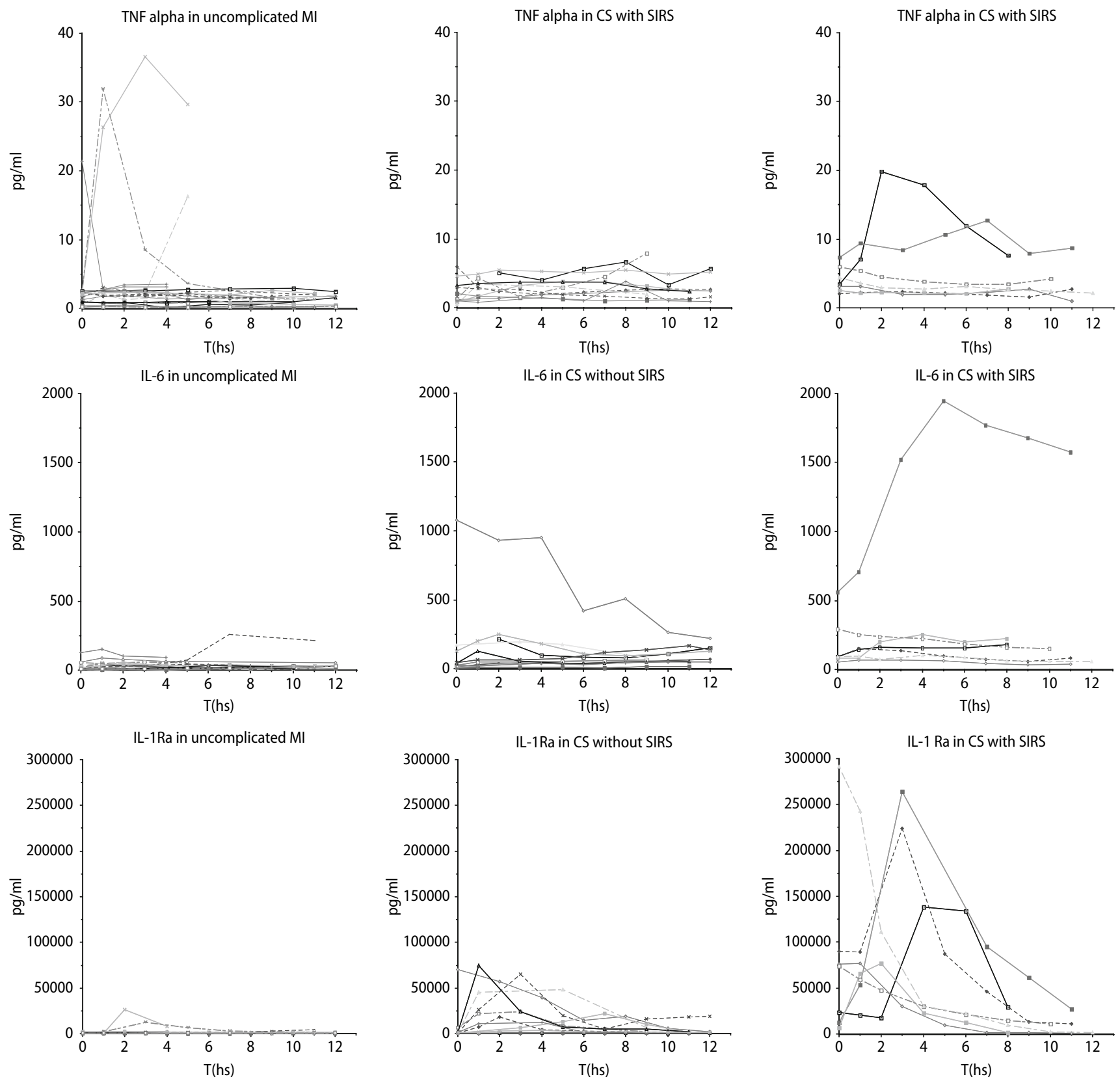

Fig. 1 Peak concentrations and reference values of IL-1Ra, IL-6 and TNF- $\alpha$ (in picograms per milliliter) for each patient. Patients are grouped based on clinical presentation as uncomplicated acute $\mathrm{MI}$, acute $\mathrm{MI}$ with cardiogenic shock, and MI with cardiogenic shock and SIRS 
tially lower than in group $2(19,988 \mathrm{pg} / \mathrm{ml}$; range $765-$ $74,379 \mathrm{pg} / \mathrm{ml} ; p=0.0006)$ and group $3(223,973 \mathrm{pg} /$ $\mathrm{ml}$; range $73,628-300,000 \mathrm{pg} / \mathrm{ml} ; p<0.0001)$.

Shock patients who developed SIRS showed an IL$1 \mathrm{Ra}$ response significantly higher than patients in CS without SIRS $(223,973 \mathrm{pg} / \mathrm{ml}$ versus $19,988 \mathrm{pg} / \mathrm{ml}$; $p=0.0005$ ) (Table 3 ). IL-1Ra was the only parameter discriminating clearly between these two groups. When comparing the first IL-1Ra level upon admission of all patients in cardiogenic shock, a significant difference with higher levels found in patients who later were developing SIRS was noted $(73,628 \mathrm{pg} / \mathrm{ml}$ versus $887 \mathrm{pg} / \mathrm{ml} ; p=0.001)$. This laboratory finding preceded the clinical findings defining a systemic inflammatory response syndrome.

\section{IL-6 and TNF- $\alpha$}

IL-6 and TNF- $\alpha$ concentrations showed similar patterns in the three patient groups. Both of these cytokines were expressed to a lower extent in patients with uncomplicated MI (see Table 3). Peak IL-6 levels of group 1 were with $34 \mathrm{pg} / \mathrm{ml}$ significantly lower when compared to group $2(109 \mathrm{pg} / \mathrm{ml}, p=0.0026)$ or group $3(253 \mathrm{pg} / \mathrm{ml}, p=0.0008)$. The lowest TNF- $\alpha$ concentrations were likewise found in hemodynamically stable patients (group 1: $2.6 \mathrm{pg} / \mathrm{ml}$ ). In comparison, the values for TNF- $\alpha$ were significantly higher in group $2(3.8 \mathrm{pg} / \mathrm{ml} ; p=0.037)$ and group 3 $(7.0 \mathrm{pg} / \mathrm{ml}, \quad p=0.012)$. Neither IL-6, nor TNF- $\alpha$ expression was significantly different in shock patients without or with SIRS (group 2 versus group 3; Table 3).

\section{CRP}

The production of $\mathrm{C}$-reactive protein in the liver is mainly induced by IL-6. The CRP-measurements generally showed higher values in more severely compromised patients. In group 1 the mean CRP-level was $35 \mathrm{mg} / \mathrm{l}$, in group $2102 \mathrm{mg} / \mathrm{l}$ and in group 3 $189 \mathrm{mg} / \mathrm{l}$. A trend towards stronger CRP-induction in sicker patients is evident. However, only the comparison of CRP concentration in group 1 and group 3 reaches statistical significance.

\section{Discussion}

Our study gives insight into inflammatory cytokine expression in patients with AMI complicated by CS as compared to patients with uncomplicated MI. Among the inflammatory markers measured, IL-1Ra was the parameter that correlated best with severity of disease. The peak concentration of IL-1Ra in patients with CS and SIRS exceeded those of patients with uncomplicated MI more than a hundred-fold. Among patients with CS there was a close correlation between the plasma concentration of proinflammatory cytokines and the clinical manifestation of a systemic inflammatory response syndrome. Moreover, an analysis of the IL-1Ra concentrations on admission demonstrates significantly higher initial IL-1Ra levels in patients who ultimately developed SIRS. Hence IL$1 \mathrm{Ra}$ was a particularly reliable indicator for poor outcome among shock patients.

\section{Cytokines measurements in ischemic heart disease and cardiogenic shock}

IL-1 is a prototypic proinflammatory cytokine with a wide range of actions both systemically and on cardiovascular level. The IL- 1 family encompasses IL- $1 \alpha$, IL- $1 \beta$ and IL- $1 \mathrm{Ra}$ and is mainly produced by monocytes and macrophages, and to a lesser degree by endothelial cells. IL-1Ra is a pure receptor antagonist of IL- $1 \alpha / \beta$ and has no other known biological activity. The immunologically active members of the IL-1 gene family IL- $1 \alpha$ and IL- $1 \beta$ are potent proinflammatory cytokines. However, IL- $1 \alpha$ and IL-1 $\beta$ lack a signal peptide and they are not readily secreted to the systemic circulation and therefore plasma level determinations are unreliable [5]. Both properties are fulfilled for IL-1Ra, and its production is increased by the same stimuli as IL- $1 \alpha$ and IL- $1 \beta$. This makes IL$1 \mathrm{Ra}$ a reliable surrogate marker for the action of the IL-1 family $[8,12]$. IL-1 is an endogenous pyrogen and some of its functions are similar to TNF- $\alpha$. IL-1 induces the production of nitric oxide, leukotriene and platelet activating factor [23]. Besides these mediators with impact on endothelial function there is an activation of gene expression for clotting factors, inhibition of fibrinolysis, endothelial passage of neutrophils and induction of endothelial adhesion molecules [23]. These mechanisms are believed to contribute greatly to the pathogenesis of acute myocardial ischemia. Hypoxia has been shown to increase the production of IL- 1 and TNF- $\alpha$ by mononuclear cells [11]. It can be assumed that extensive ischemic myocardial damage leads to local production and direct cardiac release of proinflammatory cytokines $[16,24]$.

IL-6 is a cytokine related to IL-1. The production of IL- 6 from macrophages is induced by IL- 1 and TNF- $\alpha$. Endothelial cells are capable to produce IL-6 on stimulation with a variety of inflammatory mediators [21]. IL-6 levels have been shown to be undetectable in healthy volunteers $(<3 \mathrm{pg} / \mathrm{ml})$ but are elevated with infections and inflammation [4]. High IL-6 levels are associated with poor outcome in different disease 
processes including unstable angina and septic shock $[4,6]$. IL-6 acts on hepatic cells to produce acutephase proteins like fibrinogen, $\alpha$-2-macroglobulin, serum amyloid A protein and C-reactive protein. A strong correlation has been shown between IL- 6 and CRP-levels [27]. IL-6 per se has no direct proinflammatory properties, although it is found in infection and inflammation. Unlike IL- $1 \alpha / \mathrm{IL}-1 \beta$ and TNF- $\alpha$ injection of IL-6 into humans is not associated with hypotension or systemic symptoms. IL-6 has procoagulant properties which may influence the course of acute coronary syndromes [31]. In acute MI IL-6 levels were found to be elevated on admission, before reperfusion by PCI and even before the appearance of detectable signs of necrosis [24]. As a conclusion of these findings a primary role of IL- 6 in the pathogenesis of acute MI has been suggested [24].

TNF- $\alpha$ is polypeptide with hormone-like properties. A large variety of activities of this cytokine are involved in the defense against pathogenic microorgansims and the process of tissue repair [2]. TNF- $\alpha$ derives from leukocytes/macrophages and not from endothelial cells [21]. Elevated TNF- $\alpha$ levels were found repeatedly in patients with advanced congestive heart failure [15, 20, 29]. Moreover, experimental studies have shown that TNF- $\alpha$ has a cardiotoxic effect and can produce cardiomyopathy, left ventricular remodeling and pulmonary edema $[14,22,28]$. In acute MI significant changes in TNF- $\alpha$ levels were mainly associated with extensive myocardial damage, signs of heart failure and the presence of rhythm disturbances $[16,30]$. When comparing TNF- $\alpha$ levels in blood of the coronary sinus and the aorta in patients with acute MI, there was no significant transcardiac gradient found [24]. It was concluded, that the number of leukocytes entrapped in the coronary circulation may be too small to generate detectable transcardiac TNF- $\alpha$ gradients. However, this finding does not exclude a paracrine release from these leukocytes and macrophages which may stimulate the endothelial production of IL-6.

The inflammatory reaction induced by proinflammatory cytokines has been described as a cascade of gene products which are not found in healthy persons [7]. IL- 1 and TNF- $\alpha$ are particularly effective in activating this cascade in a synergistic manner. Antiinflammatory cytokines such as IL-4, IL-10, IL-13 and transforming growth factor (TGF)-b suppress the intensity of this cascade [3]. An imbalance between pro-inflammatory and anti-inflammatory cytokines leads to a poorly antagonized acceleration of the inflammatory cascade. It is conceivable that an overwhelming pro-inflammatory response-possibly precipitated by extensive myocardial ischemia-with extraordinary high levels of IL-1 is the starting point of such a process. Another possible mechanism as a triggering factor of this cascade is an extensive myocyte damage due to reperfusion injury. The deleterious effects not only on endothelial level but also on the hemodynamic response may well explain the poor outcome of patients with these extremely high levels of plasma IL-1Ra, IL-6 and TNF- $\alpha$.

\section{Previous studies}

The inflammatory mechanism involved in acute coronary syndromes and myocardial necrosis were studied in some selected patient populations. Biasucci demonstrated not only the elevation of IL-6 in unstable angina but also the prognostic impact of cytokine levels in the course of hospitalization $[3,4]$. In this study patients with unstable angina and with a complicated hospital course had higher cytokine levels on admission. A fall of IL-1Ra and IL-6 $48 \mathrm{~h}$ after admission was associated with an uneventful course.

Neuman found in patients with acute MI before and after recanalization significantly elevated concentrations of IL-6 in the coronary sinus blood compared with the arterial blood [24]. This sophisticated technique demonstrated for the first time cardiac release of IL-6 in acute MI. It was speculated that the vascular endothelium was the predominant source of this cardiac IL- 6 . The possibility of a primary role of IL-6 in the pathogenesis of MI has been suggested. Furthermore, the possibility of important systemic effects should be assumed if cardiac liberation of IL-6 is ongoing [1].

The relative increase in TNF- $\alpha$ has been suggested as a reliable method of assessing the severity of myocardial damage after acute myocardial infarction [16]. In patients with septic shock high levels of IL-6 were found to be a particularly poor prognostic sign [6].

\section{Study limitations}

The number of patients in this single center pilot study is relatively low, reflecting also the difficulties in enrolling patients with a life-threatening condition. However, the analysis of our data is based on clearly predefined categories of patients with acute myocardial infarction. In addition, the treatment modality is homogenous throughout the whole study population, with every patient undergoing acute PCI. No data exist regarding the time frame of rise and fall of cytokine levels in this particular clinical setting. Furthermore, negative blood cultures were an exclusion criteria for coexisting sepsis. With respect to sepsis, blood cultures are poor markers because they are not positive in all patients. However, the present study was carried out at a period when procalcitonin mea- 
surements were not performed at our institution, to define infection more precisely. Finally, prognosis of patients with cardiogenic shock is determined by several clinical parameters [25] and the development of multiorgan dysfunction [19] which can be determined by the calculation of several scores (e.g., APACHE, SAPS, SOFA). These scores, however, were not performed at our institution at the time of the study protocol and to calculate these scores retrospectively makes them prone to error.

\section{Clinical perspectives}

The role of cytokines in heart disease is subject of increasing interest. Many clinical investigations have focused on cytokines in heart failure or the pathogenesis of arteriosclerosis. The main aspect of our study was to assess a subset of patients with AMI and cardiogenic shock and a particularly poor outcome due to a systemic inflammatory response. These patients did not differ from other patients in cardiogenic shock in regard to their demographic data, the infarct size, the infarct localization or treatment. The one important difference was a lower left ventricular ejection fraction in patients with cardiogenic shock and SIRS. The most important indicator for poor outcome was a markedly increased IL-1Ra levels, which were present already upon admission. In these patients the mortality rate was extremely high despite immediate and successful revascularization followed by aggressive supportive treatment. Whether IL- 1 is just an indicator for poor outcome or in fact a contributing factor cannot be determined by our study. One experimental approach to provide evidence of the causal role of this particular cytokine would be its specific blockade or neutralization. Antibodies directed against TNF- $\alpha$ and IL- 1 were used in patients with rheumatoid arthritis and Crohn's disease with few side effects $[9,10,26]$. In view of the poor prognosis of the patients with cardiogenic shock further complicated by SIRS, future studies should focus not only on the possible pathogenesis of this condition but also on possible therapeutic approaches on immunological level.

Acknowledgments We would like to acknowledge the efforts of the entire team of the central laboratory. The study would not have been possible without the dedicated efforts of the laboratory technicians and the ICU-staff of the Triemli Hospital.

\section{References}

1. Akira S, Hirano T, Taga T et al. (1990) Biology of multifunctional cytokines: IL 6 and related molecules (IL 1 and TNF). FASEB J 4:2860-2867

2. Arai KI, Lee F, Miyajima A et al. (1990) Cytokines: coordinators of immune and inflammatory responses. Annu Rev Biochem 59:783-836

3. Biasucci LM (1996) Elevated Levels of Interleukin-6 in Unstable Angina. Circulation 94:874-877

4. Biasucci LM, Liuzzo G, Fantuzzi G et al. (1999) Increasing levels of interleukin (IL)-1Ra and IL-6 during the first 2 days of hospitalization in unstable angina are associated with increased risk of in-hospital coronary events. Circulation 99:2079-2084

5. Cannon JG, Tompkins RG, Gelfand JA et al. (1990) Circulating interleukin-1 and tumor necrosis factor in septic shock and experimental endotoxin fever. J Infect Dis 161:79-84

6. Casey LC, Balk RA, Bone RC (1993) Plasma cytokine and endotoxin levels correlate with survival in patients with the sepsis syndrome. Ann Int Med 119:771-778

7. Dinarello CA (2000) Proinflammatory cytokines. Chest 118:503-508
8. Fischer E, Van Zee KJ, Marano MA et al. (1992) Interleukin-1 receptor antagonist circulates in experimental inflammation and in human disease. Blood 79:2196-2200

9. Gabay C (2002) Cytokine inhibitors in the treatment of rheumatoid arthritis. Expert Opin Biol Ther 2:135-149

10. Garces K (2001) Anakinra: interleukin1 receptor antagonist therapy for rheumatoid arthritis. Issues Emerg Health Technol 1-4

11. Ghezzi P, Dinarello CA, Bianchi M et al. (1991) Hypoxia increases production of interleukin-1 and tumor necrosis factor by human mononuclear cells. Cytokine 3:189-194

12. Granowitz EV, Santos AA, Poutsiaka DD et al. (1991) Production of interleukin-1-receptor antagonist during experimental endotoxaemia. Lancet 338:1423-1424

13. Hasdai D, Holmes DR Jr., Topol EJ et al. (1999) Frequency and clinical outcome of cardiogenic shock during acute myocardial infarction among patients receiving reteplase or alteplase. Results from GUSTO-III. Global Use of Strategies to Open Occluded Coronary Arteries. Eur Heart J 20:128135
14. Hegewisch S, Weh HJ, Hossfeld DK (1990) TNF-induced cardiomyopathy. Lancet 335:294-295

15. Herrera-Garza EH, Stetson SJ, CubillosGarzon A et al. (1999) Tumor necrosis factor-alpha: a mediator of disease progression in the failing human heart. Chest 115:1170-1174

16. Hirschl MM, Gwechenberger M, Binder $\mathrm{T}$ et al. (1996) Assessment of myocardial injury by serum tumour necrosis factor alpha measurements in acute myocardial infarction. Eur Heart J 17:1852-1859

17. Hochman JS, Sleeper LA, Webb JG et al. (1999) Early revascularization in acute myocardial infarction complicated by cardiogenic shock. SHOCK investigators. Should we emergently revascularize occluded coronaries for cardiogenic shock. N Engl J Med 341:625-634

18. Hochman JS, Sleeper LA, White HD et al. (2001) One-year survival following early revascularization for cardiogenic shock. JAMA 285:190-192

19. Kohsaka S, Menon V, Lowe AM et al. (2005) Systemic inflammatory response syndrome after acute myocardial infarction complicated by cardiogenic shock. Arch Intern Med 165:1643-1650 
20. Levine B, Kalman J, Mayer L et al. (1990) Elevated circulating levels of tumor necrosis factor in severe chronic heart failure. N Engl J Med 323:236-241

21. Mantovani A, Bussolino F, Dejana E (1992) Cytokine regulation of endothelial cell function. FASEB J 6:25912599

22. Millar AB, Foley NM, Singer $M$ et al. (1989) Tumour necrosis factor in bronchopulmonary secretions of patients with adult respiratory distress syndrome. Lancet 2:712-714

23. Moser R, Schleiffenbaum B, Groscurth $P$ et al. (1989) Interleukin 1 and tumor necrosis factor stimulate human vascular endothelial cells to promote transendothelial neutrophil passage. J Clin Invest 83:444-455
24. Neumann FJ, Ott I, Gawaz M et al. (1995) Cardiac release of cytokines and inflammatory responses in acute myocardial infarction. Circulation 92:748755

25. Schuler J, Maier B, Behrens $S$ et al. (2006) Present treatment of acute myocardial infarction in patients over 75 years. Clin Res Cardiol 95:360-367

26. Shigematsu S (1998) Therapeutic potential of interleukin-1 receptor antagonist in inflammatory bowel disease. Kurume Med J 45:175-179

27. Sturk A, Hack CE, Aarden LA et al. (1992) Interleukin-6 release and the acute-phase reaction in patients with acute myocardial infarction: a pilot study. J Lab Clin Med 119:574-579

28. Suffredini AF, Fromm RE, Parker MM et al. (1989) The cardiovascular response of normal humans to the administration of endotoxin. N Engl J Med 321:280-287
29. Torre-Amione G, Kapadia S, Lee J et al. (1996) Tumor necrosis factor-alpha and tumor necrosis factor receptors in the failing human heart. Circulation 93:704-711

30. Vaddi K (1994) Increased secretion of tumor necrosis factor- $\alpha$ and interferon$\gamma$ by mononuclear leukocytes in patients with ischemic heart disease. Circulation 90:694-699

31. van der Poll T, Levi M, Hack CE et al. (1994) Elimination of interleukin 6 attenuates coagulation activation in experimental endotoxemia in chimpanzees. J Exp Med 179:1253-1259

32. Werra Id. (1997) Cytokines, nitrite/nitrate, soluble tumor necrosis factro receptors, and procalcitonin concentrations: compaision in patients with septic shock, cardiogenic shock, and bacterial pneumonia. Crit Care Med 25:607-613 